Sigeru Omatu

José Neves

Juan M. Corchado Rodríguez

Juan F. De Paz Santana

Sara Rodríguez González (Eds.)

\title{
Distributed Computing and Artificial Intelligence
}

10th International Conference

Springer 


\section{Advances in Intelligent Systems and Computing}

\section{Volume 217}

Series Editor

J. Kacprzyk, Warsaw, Poland 
Sigeru Omatu • José Neves

Juan M. Corchado Rodríguez

Juan F. De Paz Santana

Sara Rodríguez González

Editors

\section{Distributed Computing and Artificial Intelligence}

10th International Conference

鱼 Springer 


\section{Editors}

Sigeru Omatu

Graduate School of Engineering

Osaka Prefecture University

Osaka

Japan

José Neves

Department of Computing Science

University of Minho

Braga Codex

Portugal

Juan M. Corchado Rodríguez

Department of Computing Science and Control

Faculty of Science

University of Salamanca

Salamanca

Spain
Juan F. De Paz Santana

Department of Computing Science and Control

Faculty of Science

University of Salamanca

Salamanca

Spain

Sara Rodríguez González

Department of Computing Science and Control

Faculty of Science

University of Salamanca

Salamanca

Spain
ISSN 2194-5357

ISBN 978-3-319-00550-8

DOI 10.1007/978-3-319-00551-5

Springer Cham Heidelberg New York Dordrecht London

Library of Congress Control Number: 2013937503

(C) Springer International Publishing Switzerland 2013

This work is subject to copyright. All rights are reserved by the Publisher, whether the whole or part of the material is concerned, specifically the rights of translation, reprinting, reuse of illustrations, recitation, broadcasting, reproduction on microfilms or in any other physical way, and transmission or information storage and retrieval, electronic adaptation, computer software, or by similar or dissimilar methodology now known or hereafter developed. Exempted from this legal reservation are brief excerpts in connection with reviews or scholarly analysis or material supplied specifically for the purpose of being entered and executed on a computer system, for exclusive use by the purchaser of the work. Duplication of this publication or parts thereof is permitted only under the provisions of the Copyright Law of the Publisher's location, in its current version, and permission for use must always be obtained from Springer. Permissions for use may be obtained through RightsLink at the Copyright Clearance Center. Violations are liable to prosecution under the respective Copyright Law.

The use of general descriptive names, registered names, trademarks, service marks, etc. in this publication does not imply, even in the absence of a specific statement, that such names are exempt from the relevant protective laws and regulations and therefore free for general use.

While the advice and information in this book are believed to be true and accurate at the date of publication, neither the authors nor the editors nor the publisher can accept any legal responsibility for any errors or omissions that may be made. The publisher makes no warranty, express or implied, with respect to the material contained herein.

Printed on acid-free paper

Springer is part of Springer Science+Business Media (www.springer.com) 


\section{Contents}

\section{Image Processing, Tracking, Robotic, Control and Industrial Systems}

Improving the Performance of NEAT Related Algorithm via

Complexity Reduction in Search Space . . . . . . . . . . . . . . . .

Heman Mohabeer, K.M.S. Soyjaudah

Intelligent Application to Reduce Transit Accidents

in a City Using Cultural Algorithms . . . . . . . . . . . . . . .

Fernando Maldonado, Alberto Ochoa, Julio Arreola, Daniel Azpeitia,

Ariel De la Torre, Diego Canales, Saúl González.

Synchronization Policies Impact in Distributed Agent-Based

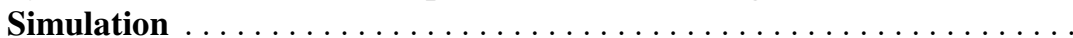

Omar Rihawi, Yann Secq, Philippe Mathieu

Parallel Hoeffding Decision Tree for Streaming Data . . . . . . . . . . . 27

Piotr Cal, Michat Woźniak

Stochastic Decentralized Routing of Unsplittable Vehicle Flows Using

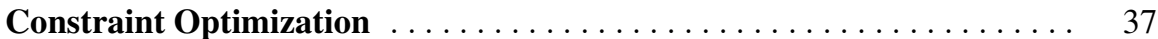

Maksims Fiosins

Extending Semantic Web Tools for Improving Smart Spaces

Interoperability and Usability .

Natalia Díaz Rodríguez, Johan Lilius, Manuel Pegalajar Cuéllar, Miguel Delgado Calvo-Flores

OPTICS-Based Clustering of Emails Represented by Quantitative

Profiles

Vladimír Špitalský and Marian Grendár 
Optimal Saving and Prudence in a Possibilistic

Framework

Ana Maria Lucia Casademunt, Irina Georgescu

Semantic Annotation and Retrieval of Services

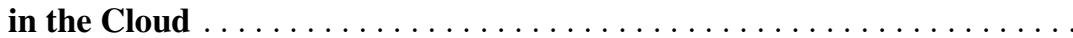

Miguel Ángel Rodríguez-García, Rafael Valencia-García,

Francisco García-Sánchez, José Javier Samper-Zapater,

Isidoro Gil-Leiva

Simulating a Team Behaviour of Affective Agents Using Robocode . . . . .

António Rebelo, Fábio Catalão, João Alves, Goreti Marreiros,

Cesar Analide, Paulo Novais, José Neves

\section{New Algorithms}

Qualitative Acceleration Model: Representation, Reasoning

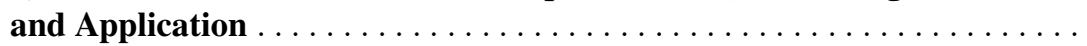

Ester Martinez-Martin, Maria Teresa Escrig, Angel P. del Pobil

Framework of Optimization Methodology with Use of an Intelligent Hybrid Transport Management System Based on Hopfield Network and Travelling Salesman Problem .

Natalia Kubiak, Agnieszka Stachowiak

Selecting the Shortest Itinerary in a Cloud-Based Distributed Mobility

Network ...............................

Jelena Fiosina, Maksims Fiosins

Application of Genetic Algorithms to Determine Closest Targets in Data Envelopment Analysis .

Raul Martinez-Moreno, Jose J. Lopez-Espin, Juan Aparicio,

Jesus T. Pastor

Odor Classification Based on Weakly Responding Sensors

Sigeru Omatu, Mitsuaki Yano, Toru Fujinaka

A Model to Visualize Information in a Complex Streets' Network

Taras Agryzkov, José L. Oliver, Leandro Tortosa, José F. Vicent

Case-Based Reasoning Applied to Medical Diagnosis and Treatment . . . .

Xiomara Blanco, Sara Rodríguez, Juan M. Corchado, Carolina Zato

Multiple Agents for Data Processing

Ichiro Satoh

Migrants Selection and Replacement in Distributed Evolutionary

Algorithms for Dynamic Optimization

Yesnier Bravo, Gabriel Luque, Enrique Alba 


\section{Multi-agent Systems}

Ubiquitous Computing to Lower Domestic Violence Rate Based on Emotional Support Social Network (Redsiam) . . . . . . . . . . 163 Maria De Lourdes Margain, Guadalupe Obdulia Gutiérrez, Begoña García, Amaia Méndez, Alberto Ochoa, Alejandro de Luna, Gabriela Hernández.

Multiobjective Local Search Techniques for Evolutionary Polygonal Approximation

José L. Guerrero, Antonio Berlanga, José M. Molina

GSched: An Efficient Scheduler for Hybrid CPU-GPU HPC Systems . .

Mariano Raboso Mateos, Juan Antonio Cotobal Robles

\section{Comparison of K-Means and Fuzzy C-Means Data Mining}

Algorithms for Analysis of Management Information:

An Open Source Case

Angélica Urrutia, Hector Valdes, José Galindo

Mobile-Based Distributed System for Managing Abandoned or Lost

Pets

Daniel Garrote-Hildebrand, José-Luis Poza-Luján,

Juan-Luis Posadas-Yagüe, José-Enrique Simó-Ten

Robust Optimization of Intradomain Routing Using Evolutionary

Algorithms

Vitor Pereira, Pedro Sousa, Paulo Cortez, Miguel Rio,

Miguel Rocha

A MAS for Teaching Computational Logic

Jose Alberto Maestro-Prieto, $M^{a}$ Aránzazu Simón-Hurtado,

Juan F. de-Paz-Santana, Gabriel Villarrubia-González.

Fast Post-Disaster Emergency Vehicle Scheduling

Roberto Amadini, Imane Sefrioui, Jacopo Mauro,

Maurizio Gabbrielli

Creating GPU-Enabled Agent-Based Simulations Using

a PDES Tool

Worawan Marurngsith, Yanyong Mongkolsin

Agent and Knowledge Models for a Distributed Imaging System . . . . . . 235 Naoufel Khayati, Wided Lejouad-Chaari

DPS: Overview of Design Pattern Selection Based on MAS

Technology .

Eiman M. Salah, Maha T. Zabata, Omar M. Sallabi 
Representing Motion Patterns with the Qualitative Rectilinear

Projection Calculus .

Francisco Jose Gonzalez Cabrera, Jose Vicente Álvarez-Bravo,

Fernando Díaz

Event Management Proposal for Distribution Data Service Standard . . 259 José-Luis Poza-Luján, Juan-Luis Posadas-Yagüe,

José-Enrique Simó-Ten

Trajectory Optimization under Changing Conditions

through Evolutionary Approach and Black-Box Models

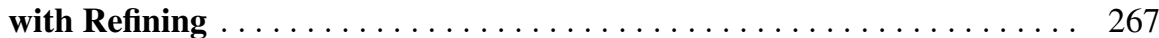

Karel Macek, Jiři Rojíček, Vladimír Bičík

Modelling Agents' Risk Perception

Nuno Trindade Magessi, Luis Antunes

On the Use of PSO with Weights Adaptation in Concurrent

Multi-issue Negotiations .

Kakia Panagidi, Kostas Kolomvatsos, Stathes Hadjiefthymiades

Monitoring Weight and Physical Activity Using an AmI Setting

João Ferreira, Rafaela Rosário, Ângelo Costa, Paulo Novais

\section{Distributed Computing, Grid Computing, Cloud Computing}

An Emotional Aware Architecture to Support Facilitator in Group Idea Generation Process .

João Laranjeira, Goreti Marreiros, João Carneiro, Paulo Novais

Social Networks Gamification for Sustainability Recommendation

Systems . . . . . . . . . . . . . . . . . . . . . . . . . . . . 307

Fábio Silva, Cesar Analide, Luís Rosa, Gilberto Felgueiras,

Cedric Pimenta

Web-Based Solution for Acquisition, Processing, Archiving

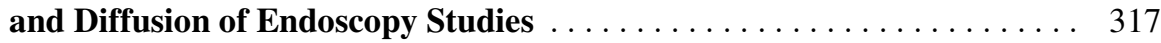

Isabel Laranjo, Joel Braga, Domingos Assunção, Andreia Silva, Carla Rolanda, Luís Lopes, Jorge Correia-Pinto, Victor Alves

Texture Classification with Neural Networks

William Raveane, María Angélica González Arrieta

A Context Aware Architecture to Support People with Partial Visual Impairments

João Fernandes, João Laranjeira, Paulo Novais, Goreti Marreiros, José Neves 
Automatic Prediction of Poisonous Mushrooms by Connectionist

Systems

María Navarro Cáceres, María Angélica González Arrieta

Adaptive Learning in Games: Defining Profiles of Competitor

Players

Tiago Pinto, Zita Vale

\section{Bioinformatics, Biomedical Systems, e-health, Ambient Assisting Living}

Associative Learning for Enhancing Autonomous Bots in Videogame

Design .

Sergio Moreno, Manuel G. Bedia, Francisco J. Serón,

Luis Fernando Castillo, Gustavo Isaza

An Integral System Based on Open Organization of Agents

for Improving the Labour Inclusion of Disabled People .

Alejandro Sánchez, Carolina Zato, Gabriel Villarrubia-González,

Javier Bajo, Juan Francisco De Paz

+Cloud: An Agent-Based Cloud Computing Platform

Roberto González, Daniel Hernández, Fernando De la Prieta,

Ana Belén Gil

Representation of Propositional Data for Collaborative Filtering

Andrzej Szwabe, Pawel Misiorek, Michal Ciesielczyk

Face Identification by Real-Time Connectionist System

Pedro Galdámez, Angélica González

QoS Synchronization of Web Services: A Multi Agent-Based Model . . . 401 Jaber Kouki, Walid Chainbi, Khaled Ghedira

\section{Data mining, Information Extraction, Semantic,} Knowledge Representation

Comparing Basic Design Options for Management Accounting Systems with an Agent-Based Simulation

Friederike Wall

Potential Norms Detection in Social Agent Societies

Moamin A. Mahmoud, Aida Mustapha,

Mohd Sharifuddin Ahmad, Azhana Ahmad, Mohd Zaliman M. Yusoff,

Nurzeatul Hamimah Abdul Hamid

Collision Avoidance of Mobile Robots Using Multi-Agent Systems

Angel Soriano, Enrique J. Bernabeu, Angel Valera, Marina Vallés 
Multi-agent Architecture for Intelligent Insurance

Systems .

Egons Lavendelis

Evaluation Framework for Statistical User Models

Javier Calle, Leonardo Castaño, Elena Castro, Dolores Cuadra

Agent Mediated Electronic Market Enhanced with Ontology Matching Services and Emergent Social

Networks

Virgínia Nascimento, Maria João Viamonte, Alda Canito,

Nuno Silva

\section{Artificial Intelligence Applications}

Semantic Multi-agent Architecture to Road Traffic Information

Retrieval on the Web of Data .

José Javier Samper-Zapater, Dolores M. Llidó Escrivá,

Juan José Martínez Durá, Ramon V. Cirilo

Personalised Advertising Supported by Agents

Bruno Veloso, Luís Sousa, Benedita Malheiro

Two Approaches to Bounded Model Checking for a Soft Real-Time

Epistemic Computation Tree Logic

Artur Męski, Bożena Woźna-Szcześniak, Agnieszka M. Zbrzezny,

Andrzej Zbrzezny

Towards an AOSE: Game Development Methodology

Rula Al-Azawi, Aladdin Ayesh, Ian Kenny,

Khalfan Abdullah AL-Masruri

Periodic Chemotherapy Dose Schedule Optimization Using Genetic

Algorithm .

Nadia Alam, Munira Sultana, M.S. Alam, M.A. Al-Mamun,

M.A. Hossain

Mobile-Agent Based Delay-Tolerant Network Architecture

for Non-critical Aeronautical Data Communications . . . . . . . . . . . . 513

Rubén Martínez-Vidal, Sergio Castillo-Pérez, Sergi Robles,

Miguel Cordero, Antidio Viguria, Nicolás Giuditta

A Preliminary Study on Early Diagnosis of Illnesses Based on Activity

Disturbances ............................. 521

Silvia González, José R. Villar, Javier Sedano, Camelia Chira 
Towards an Adaptable Mobile Agents' Management

System

Mohammad Bashir Uddin Khan, Ghada Abaza, Peter Göhner

Glove-Based Input for Reusing Everyday Objects as Interfaces

in Smart Environments.

Ionuţ-Alexandru Zaiţi, Ştefan-Gheorghe Pentiuc

Suboptimal Restraint Use as an Emergent Norm via Social Influence . . $\quad 545$ Felicitas Mokom, Ziad Kobti

Implementing MAS Agreement Processes Based on Consensus

Networks

Alberto Palomares, Carlos Carrascosa, Miguel Rebollo, Yolanda Gómez

Agent-Based Interoperability for e-Government

Fábio Marques, Gonçalo Paiva Dias, André Zúquete

Context- and Social-Aware User Profiling for Audiovisual

Recommender Systems . . . . . . . . . . . . . . . . . . . . . . . . . . 569

César A. Mantilla, Víctor Torres-Padrosa, Ramón Fabregat

Current Trends in Bio-Ontologies and Data Integration . . . . . . . . . . . 579

Rafael Pereira, Rui Mendes

Challenges in Development of Real Time Multi-Robot System Using

Behaviour Based Agents . . . . . . . . . . . . . . . . . . . 587

Aleksis Liekna, Egons Lavendelis, Agris Nikitenko

Application of Hybrid Agents to Smart Energy Management

of a Prosumer Node . . . . . . . . . . . . . . . . . . . . . . . . . . . . . . . . . . 597

Pasquale Caianiello, Stefania Costantini, Giovanni De Gasperis,

Niva Florio, Federico Gobbo

Structuring and Exploring the Biomedical Literature Using Latent

Semantics . . . . . . . . . . . . . . . . . . . . . . . . . . . . . 609

Sérgio Matos, Hugo Araújo, José Luís Oliveira

Upper Ontology for Multi-Agent Energy Systems' Applications . . . . . . . 617

Gabriel Santos, Tiago Pinto, Zita Vale, Hugo Morais, Isabel Praça

A Practical Mobile Robot Agent Implementation Based on a Google Android Smartphone . . . . . . . . . . . . . . . . . . . . . . . . . . . . 625

Dani Martínez, Javier Moreno, Davinia Font, Marcel Tresanchez,

Tomàs Pallejà, Mercè Teixidó, Jordi Palacín 
Cloud-Based Platform to Labor Integration of Deaf

People

Amparo Jiménez, Amparo Casado, Javier Bajo,

Fernando De la Prieta, Juan Francisco De Paz

\section{Erratum}

Mobile-Agent Based Delay-Tolerant Network Architecture

for Non-critical Aeronautical Data Communications . .

Rubén Martínez-Vidal, Sergio Castillo-Pérez, Sergi Robles,

Miguel Cordero, Antidio Viguria, Nicolás Giuditta

Author Index 


\title{
An Integral System Based on Open Organization of Agents for Improving the Labour Inclusion of Disabled People
}

\author{
Alejandro Sánchez, Carolina Zato, Gabriel Villarrubia-González, Javier Bajo, \\ and Juan Francisco De Paz \\ Departamento Informática y Automática, Universidad de Salamanca \\ Plaza de la Merced s/n, 37008, Salamanca, Spain \\ \{sanchezyu, carol_zato,gvg, jbajope,fcofds\}@usal.es
}

\begin{abstract}
This paper presents a system composed by a set of tools that facilitate the work of disabled people in their work environment. The PANGEA platform was used to build the base architecture of the system, where each tool is designed as a collection of intelligent agents that offer the services as Web-services. Moreover, all the system is implemented as an Open MAS. In this paper two tools are presented in detail, the proximity detection tool and the translator tool for people with hearing impairments.
\end{abstract}

Keywords: personalization workplace, disabled people, open MAS, agent platform, Zigbee, proximity detection, localization.

\section{Introduction}

Modern societies are characterized by two trends. The first is the rapid development of technologies, which has influenced our lives in many different ways. The second is the effort among governments, companies and associations toward enabling people with disabilities to have an independent life, which includes the possibility for remunerative employment. The effective integration of people with disabilities in the workplace is a huge challenge to society, and it presents an opportunity to make use of new technologies.

This paper presents a collection of tools that are being developed to formed an integral intelligent system. The different tools for the disabled people have been modelled with intelligent agents that use Web services. These agents are implemented and deployed within the PANGEA platform so they form an integral system that can be used regardless of their physical location or implementation. This project aims to develop new technologies that contribute to the employment of groups of people with visual, hearing or motor disabilities in office environments. Some of these tools are a head mouse to control the mouse with the eyes, a vibrator bracelet to send Morse messages, an avatar for the hearing impaired, a location system, etc. But due to space limitation, in this paper just an avatar and a proximity detection tool are presented. 
The rest of the paper is structured as follows: The next section introduces the basis of open MAS and the PANGEA platform. Section 3 presents the proximity prototype tool. Section 4 explains the translator tool. Next, section 5 presents a case study. Finally, in section 6 some conclusions are presented.

\section{Open MAS}

Open MAS can be understood as the following step in multi-agent systems. These are systems in which the structure is able to change dynamically. Its components are not known a priori, change over time and may be heterogeneous. The open MAS must allow the participation of heterogeneous agents with different architectures and even languages [18]. This makes it difficult to rely on the agents' behavior, and necessitates controls based on societal norms or rules. The proposed system has been designed as an open MAS.

Nowadays, there are many multi-agent systems which help and facilitate the work with the agents $[1,8,5]$. The only inconvenience of these systems is that they are for general purpose. The architecture that will be used in this paper must be able to assume the tasks for the integration of the persons with disabilities to the workplace. In this line, the most known works are:

- The European project CommonWell [2] proposes an architecture to support European citizens with limited mobility, or a hearing or visual impairment. However, it focuses on the elderly and does not incorporate either advanced adaptive interfaces or identification and localization elements.

- The European project DTV4A11 [3] proposes the use of digital television to integrate persons with disabilities, but it relies on the television as the only mechanisms to provide services.

- The European project MonAMI [15] proposes a global framework to offer services to the elderly and handicapped, but it focuses on providing these individuals with a more independent lifestyle.

At a Spanish national level we can find:

- The DISCATEL project [4] aims to incorporate persons with disabilities to Contact Centers or allow them to telecommute from their home or residence.

- The INREDIS project (Interfaces for the Relationship between people with Disabilities) [11] is a CENIT project headed by Technosite, which is investigating the concept of using personal devices with interoperability and ubiquitous characteristics to strengthen accessibility of persons with disabilities..

- The eVia platform has the INCLUTEC [10] study group, which is oriented toward analysis, and promotes the use and development of mobility mechanisms, such as assisted wheelchairs and specialized vehicle, alternative and enhanced communication, manipulation, and cognition.

None of this multiagent platforms shown previously, adapt to our requirements because most of them focus on the elderly or on the social integration of people with disabilities, instead of our goal, which is the labor inclusion of this kind of 
people. PANGEA architecture whose novelty is a dynamic and adaptable architecture capable of integrating new services for incorporating persons with visual, hearing, or mobile impairments into the workforce.

\subsection{Description of PANGEA}

PANGEA [20] is a service oriented platform that allows the implemented open MAS to take maximum advantage of the distribution of resources. To this end, all services are implemented as Web Services. Due to its service orientation, different tools modeled with agents that consume Web services can be integrated and operated from the platform, regardless of their physical location or implementation. This makes it possible for the platform to include both a service provider agent and a consumer agent, thus emulating a client-server architecture. The provider agent (a general agent that provides a service) knows how to contact the web service, while the remaining agents know how to contact with the provider agent due to their communication with the ServiceAgent, which contains information about services.

Once the client agent's request has been received, the provider agent extracts the required parameters and establishes contact. Once received, the results are sent to the client agent. Using Web Services also allows the platform to introduce the SOA (Service-oriented Architecture) [12] into MAS systems. SOA is an architectural style for building applications that use services available in a network such as the web. It promotes loose coupling between software components so that they can be reused. Applications in SOA are built based on services.

\section{Proximity Detection Tool}

The proximity detection system is based on the detection of presence using the ZigBee Technology [19]. Every computer in the room must have a Zigbee router assigned, and the system have to know their exact positions at every moment. Furthermore, all the users have to carry a Zigbee tag (Figure 1), which is responsible for the identifying each of them. Once the Zigbee tag carried by the person has been detected and identified, its location is delimited within the proximity of the sensor that identified it.

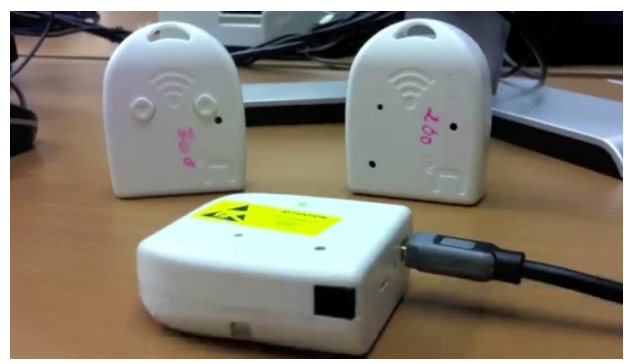

Fig. 1 Zigbee tags 
The agents that composed the tool are deployed in a specialized suborganization inside PANGEA, each one of these agents offer services (like a localization service) modeled as Web Services. The platform agents are implemented with Java, while the agents of the detection prototype are implemented in .NET and nesC.

Every user in the proposed system carries a Zigbee tag, which is detected by a ZigBeeReaderAgent located in each system terminal and continuously in communication with the ClientComputerAgent. Thus, when a user tag is sufficiently close to a specific terminal (within a range defined according to the strength of the signal), the ZigBeeReaderAgent can detect the user tag and immediately send a message to the ClientComputerAgent. The parameter RSSI is the responsible of measuring the receiving signal strength. The values fluctuate from an initial 0 to negative values. If values are close 0 , the user tag is near a computer. If the user moves away the workplace, values begin to be negatives. For switching on the computers, the Wake-on-LAN protocol is used due to the system uses a LAN infrastructure [16] [13].

Next, this agent communicates the tag identification to the UsersProfileAgent, which consults the database to create the xml file that is returned to the ClientComputerAgent. The ClientComputerAgent then interacts with the ServiceAgent to invoke the Web Services needed to personalize the computer according to the user's profile.

In Figure 2 the interface of the tool is shown. In the upper part, the main controller has options to manage computers, events, sensors and users. And below, the information about the identification once the ClientComputerAgent has finished the communication process with the UsersProfileAgent.

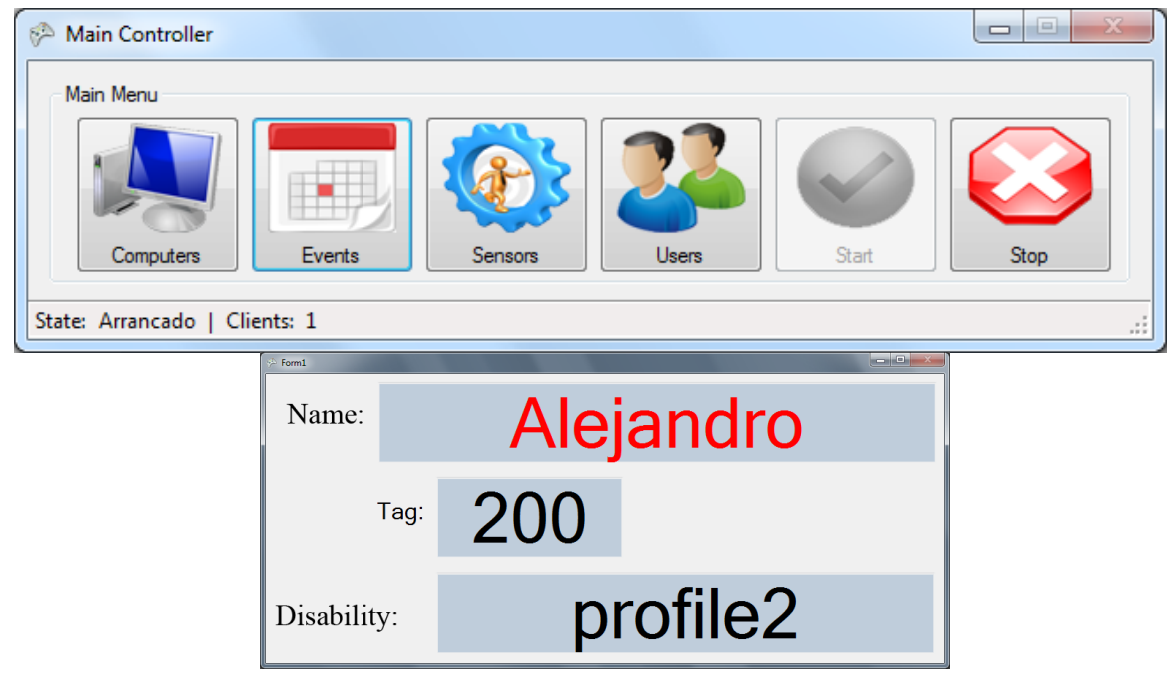

Fig. 2 Interface of the system 


\section{Translator Tool}

This tool emerged as a result of the difficulty encountered by employers in communicating to their hearing impaired employees the actions that they have to do in their jobs. Given the ineffectiveness of avatar translators, the solution chosen was to study the main communication needs and provide some recorded videos with commands and explanations specifically related to the performance of a particular job.

Once the computer has been switched on and personalized thanks to the proximity detection tool, the worker with a hearing impairment will see automatically the avatar on his screen. As can be seen in the figure 3, the avatar appears on the screen to indicate to the user the tasks that must be performed on this workday. The boss can send the tasks through email or text message, and the worker will receive them on the computer screen.

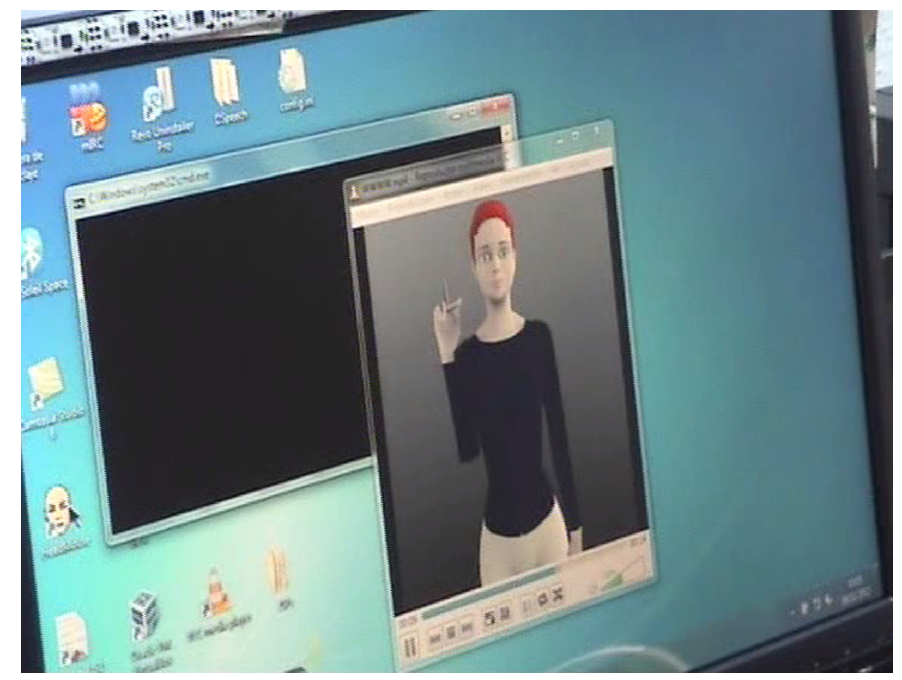

Fig. 3 Avatar of the translator tool

The issuing agents, deployed on both Smartphones (Android or iPhone) or computers, will be responsible for playing the video required at each moment. Receptor agents, also available for Smartphones or computers, will be responsible for capturing by text or by voice, the command or instruction that the employer wishes to transmit to the disabled employee.

In PANGEA, the translator agent is called VideoTranslatorAgent and it is deployed within the suborganization TranslatorOrganization. VideoTranslatorAgent is responsible for receiving the instruction and mapping the specific video used by the emitter agent who is requesting the transfer. The figure 4 shows all the agents involved in the functioning of the tool. 


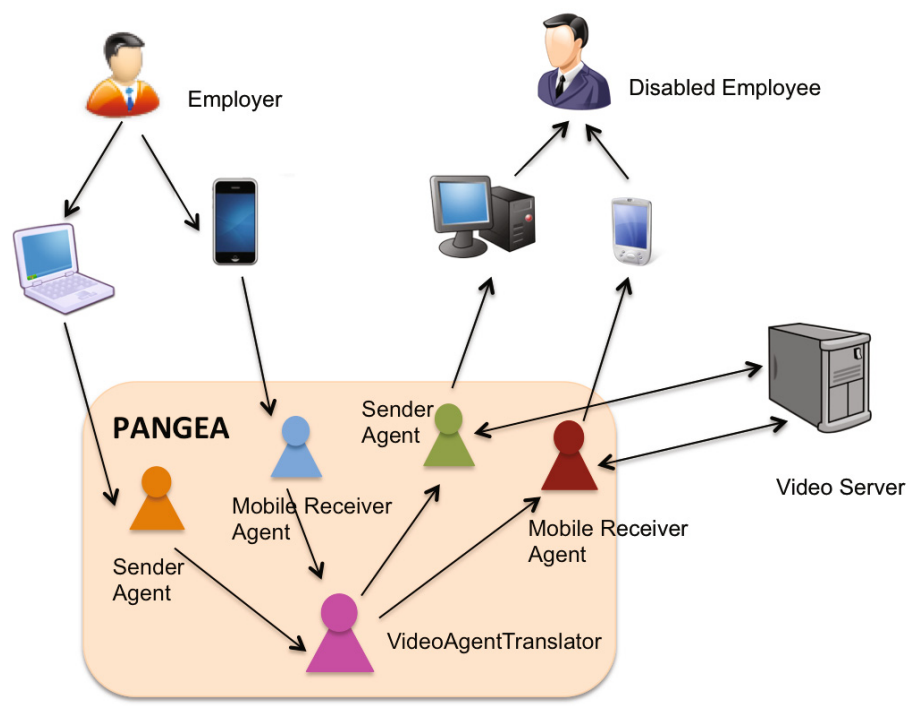

Fig. 4 Agents of the translator tool deployed in PANGEA

\section{Case Study}

All the tests have been centered on the final user. Tests have been carried out with individuals with different disabilities and a user profile exists for each person. User profiles stored data related to applications that are useful to users. These data can be classified according to the application, as shown in the following table.

Table 1 Data stored to personalize the computer

\begin{tabular}{|l|l|l|}
\hline \multicolumn{2}{|c|}{ Screen } \\
\hline Parameter & Value & Description \\
\hline usage & $1 / 0$ & $\begin{array}{l}\text { Field to describe if } \\
\text { this tool is used. }\end{array}$ \\
\hline invertColourChoice & $\begin{array}{l}\text { Field to describe if } \\
\text { the colors are } \\
\text { inverted. }\end{array}$ \\
\hline magnification & $1-200$ & $\begin{array}{l}\text { Field to describe the } \\
\text { level of magnification } \\
\text { the user want on the } \\
\text { screen. }\end{array}$ \\
\hline Parameter & Value & Avatar \\
\hline usage & Preferred/unpreferred & $\begin{array}{l}\text { Description to describe if this } \\
\text { tool is used. }\end{array}$ \\
\hline velocity & $1-10$ & $\begin{array}{l}\text { Field to describe the } \\
\text { speed of the signs. }\end{array}$ \\
\hline suze & $1-10$ & $\begin{array}{l}\text { Field to indicate the size } \\
\text { of the avatar }\end{array}$ \\
\hline localization & $1-10$ & $\begin{array}{l}\text { Field to where the avatar } \\
\text { is displayed on the } \\
\text { screen }\end{array}$ \\
\hline
\end{tabular}


Table 1 (continued)

\begin{tabular}{|l|l|l|}
\hline \multicolumn{3}{|c|}{ Language } \\
\hline Parameter & Value & Description \\
\hline lenguage & ISO 3166-1 alfa-3 & $\begin{array}{l}\text { Field to describe the user's } \\
\text { language }\end{array}$ \\
\hline \multicolumn{3}{|c|}{ Virtual Keyboard } \\
\hline Parameter & Value & Description \\
\hline usage & Preferred/unpreferred & $\begin{array}{l}\text { Field to describe if this } \\
\text { tool is used. }\end{array}$ \\
\hline \multicolumn{3}{|c|}{ Head Mouse } \\
\hline Parameter & Value & Description \\
\hline usage & Preferred/unpreferred & $\begin{array}{l}\text { Field to describe if } \\
\text { this tool is used. }\end{array}$ \\
\hline cursorAcceleration & $1-10$ & $\begin{array}{l}\text { Field to describe the } \\
\text { accelerating the } \\
\text { cursor. }\end{array}$ \\
\hline cursorSpeed & $1-10$ & $\begin{array}{l}\text { Field to describe the } \\
\text { speed of the cursor }\end{array}$ \\
\hline
\end{tabular}

The tests have helped us to fix the correct values and to refine the functioning of these tools.

\section{Conclusions}

This system is specifically oriented to facilitate the integration of people with disabilities into the workplace. Thanks of the PANGEA platform, the system can be easily designed and deployed since the platform itself provides agents and tools for the control and management of any kind of open MAS or VO. Moreover, the platform makes it possible to deploy different agents, even those included in the mobile devices, and communicates with the agents embedded in the Zigbee sensors. On the other hand, due to the based-on-services PANGEA implementation, the system has a high scalability and more tools can be added easily.

The presented system offers a multiagent system which is able to communicate with a proximity detection system and to personalize the workspace to improve the adaptation to the company flow. This individual adaptation allows that, whatever the disability the person has, the workplace will be adapted automatically, facilitating his productivity and removing the existing barriers, as the case of turning on the computer with the proximity detection system. Moreover, the translator tool will facilitate the communication in case the worker has hearing impairments.

Acknowledgements. This research has been supported by the project OVAMAH (TIN2009-13839-C03-03) funded by the Spanish Ministry of Science and Innovation.

\section{References}

1. Agent Oriented Software Pty Ltd., JACK ${ }^{\mathrm{TM}}$ Intelligent Agents Teams Manual. Agent Oriented Software Pty Ltd. (2005)

2. CommonWell Project (2010), http: / / commonwell .eu / index.php 
3. Digital Television for All project (2010), http: / /www . psp-dtv4all .org/

4. DISCATEL (2010), http: //www. imsersounifor.org/proyectodiscatel/

5. Galland, S.: JANUS: Another Yet General-Purpose Multiagent Platform. Seventh AOSE Technical Forum, Paris (2010)

6. Giunchiglia, F., Mylopoulos, J., Perini, A.: The tropos software development methodology: Processes, models and diagrams. In: Giunchiglia, F., Odell, J.J., Weiss, G. (eds.) AOSE 2002. LNCS, vol. 2585, pp. 162-173. Springer, Heidelberg (2003)

7. Huang, Y., Pang, A.: A Comprehensive Study of Low-power Operation in IEEE 802.15.4. In: Proceeding of the 10th ACM Symposium on Modeling, Analysis and Simulation of Wireless and Mobile Systems, Chaina, Crete Island, Greece (2007)

8. Hübner, J.F.: J -Moise+ Programming organisational agents with Moise+ \& Jason. Technical Fora Group at EUMAS 2007 (2007)

9. Ilyas, M., Dorf, R.C.: The handbook of ad hoc wireless networks. CRC Press Inc., Boca Raton (2003)

10. INCLUTEC (2011), http: / / www. idi.aetic.es/evia/es/inicio/ contenidos/documentacion/documentacion_grupos_de_trabajo/ contenido.aspx

11. INREDIS (2011), http: / /www. inredis.es /

12. Josuttis, N.M.: SOA in Practice. O’Reilly Media, Inc. (2007)

13. Lieberman, P.: Wake on LAN Technology, White paper (2011), http: //www. liebsoft.com/pdfs/Wake_On_LAN.pdf

14. Martin, D., et al.: OWL-S: Semantic Markup for Web Services, W3C Member Submission (2004), http: / / www .w3 . org/Submission/OWL-S /

15. Monami project (2010), http: / / www . monami . info/

16. Nedevschi, S., Chandrashekar, J., Liu, J., Nordman, B., Ratnasamy, S., Taft, N.: Skilled in the art of being idle: reducing energy waste in networked systems. In: Proceedings of the 6th USENIX Symposium on Networked Systems Design and Implementation, Boston, Massachusetts, pp. 381-394 (2009)

17. Razavi, R., Perrot, J.-F., Guelfi, N.: Adaptive modeling: An approach and a method for implementing adaptive agents. In: Ishida, T., Gasser, L., Nakashima, H. (eds.) MMAS 2005. LNCS (LNAI), vol. 3446, pp. 136-148. Springer, Heidelberg (2005)

18. Zambonelli, F., Jennings, N.R., Wooldridge, M.: Developing multiagent systems: The Gaia methodology. ACM Transactions on Software Engineering and Methodology 12(3), 317-370 (2003)

19. ZigBee Standards Organization: ZigBee Specification Document 053474r13. ZigBee Alliance (2006)

20. Zato, C., et al.: PANGEA - platform for automatic coNstruction of orGanizations of intElligent agents. In: Omatu, S., Paz Santana, J.F., González, S.R., Molina, J.M., Bernardos, A.M., Rodríguez, J.M.C. (eds.) Distributed Computing and Artificial Intelligence. AISC, vol. 151, pp. 229-240. Springer, Heidelberg (2012) 


\title{
Cloud-Based Platform to Labor Integration of Deaf People
}

\author{
Amparo Jiménez ${ }^{1}$, Amparo Casado ${ }^{1}$, Javier Bajo ${ }^{2}$, Fernando De la Prieta ${ }^{3}$, \\ and Juan Francisco De Paz ${ }^{3}$ \\ ${ }^{1}$ Universidad Pontificia de Salamanca, Salamanca, Spain \\ \{ajimenezvi, acasadome\} @upsa.es \\ ${ }^{2}$ Department of Computer Science and Automation Control, \\ Universidad de Salamanca, Plaza de la Merced s/n, 37007, Salamanca, Spain \\ $\{$ fer, fcofds\} @usal.es \\ ${ }^{3}$ Departamento de Inteligencia Artificial, Universidad Politécnica de Madrid \\ javier.bajo@upm.es
}

\begin{abstract}
The new model of labor relations established by the Spanish Royal Decree-Law (3/2012) on urgent measures for labor reform has among its objectives the promotion of inclusion in the labor market of more advantaged groups, including the people with disabilities. This paper presents a cloud-based platform aimed at obtaining an on-line workspace to provide facilities to inform, train and evaluate the competencies of disabled people, and more specifically those skills required to facilitate the labor integration of individuals with auditory disabilities. This platform presented in this paper has been tested in a real environment and the results obtained are promising.
\end{abstract}

Keywords: disabled people, auditory disability, competence, intelligent systems, learning and training processes.

\section{Introduction}

Nowadays, the context of education and training for disabled people has acquired a growing relevance, especially for labor integration. Information and communication technologies play a very important role in this evolution. This study presents a research project, carried out during past year that was focused on two different realities: professional training and proper professional performance with the special needs, such as auditory disabled people, of some people with difficulties to access to employment.

Within this study, the target term auditory disabled refers to a person on with hearing difficulty that can be alleviated with technical aids (FESORCV) [2], as well as Prieto indicates [1]. In other words, people with a degree of disability (now disabled) greater than $33 \%$ by deafness or hearing limitations that encounter communication barriers (Spanish Law 27/2007, of 23 October, recognizing the 
Spanish sign languages and regulates the means of support for oral communication of the deaf, hearing impaired and deaf-blind, 2007) [3], or as a term currently used for the Confederation of Deaf People (CNSE) [4] or the Spanish Confederation of Deaf Families [5].

The study started with the selection of a target group of deaf people in a specific job profile and its performance: Auxiliary Operations and General Administrative Services. Subsequently, a technology-based training tool had developed which allows the disabled people to effectively develop their professional performance, as well as to improve the professional training previous to the integration into the labor environment. In order to perform a proper design of this professional guidance, it is necessary to detail and analysis the specific characteristics of the position, profile and skills associated with their good work performance.

These skills have to be acquired by the worker, by means of professional qualification, in order to achieve the goals of the position. As Spanish Law 5/2002 on Qualifications and Vocational Training [6] states professional qualification is the "set of skills with significance in employment that can be acquired through training or other types of modular training, and through work experience". From a formal point of view, the qualification is the set of professional competencies (knowledge, skills, abilities, motivations) that allow us to perform occupations and jobs with a valuable labor market impact and that can be acquired through training or work experience.

Thus, we propose a cloud-based platform that focuses on obtaining on-line workspace for exchanging digital contents in an easy, intuitive and accessible manner. The main objective of the platform is to provide facilities to inform, train and evaluate the competencies of disabled people, and more specifically those skills required to facilitate the labor integration of individuals with auditory disabilities. This process may take place in the workplace or in the place of address via television, computer and mobile phone.

The rest of the paper is structured as follows: section 3 presents the problem formalization, section 4 describes the developed technological platform and, finally, section 5 presents the preliminary results and the conclusions obtained.

\section{Problem Formalization}

Our aim is not to find a professional qualification which corresponds to the Initial Professional Qualification Programmes (PCPI) but, based on the characteristics and requirements related to the position as identified in the Spanish Royal Decree 229/2008 of 1 February (BOE, No. 44 of February 20, 2008) [7], the objective is to identify some actions, strategies and more appropriate training resources, technologically updated and valid for the training and evaluation of the disabled individuals. The formalization of the problem as relied on the Spanish Catalogue of Professional Qualifications and professional qualifications and an Auxiliary Operations and Administrative Services for the Family General Administration and Management Professional with Level 1 were selected. 
From our point of view, it is essential to follow the determination of the legal requirements and current proposals in the employment context. This allow us to train competent workers taking into account the parameters required in our sociolabor context, as well as the parameters shared by any worker (with or without disabilities) to develop such activities.

We define, therefore, and employment and social integration strategy for people with different skills but that can afford with guarantees the demands of the position. Therefore, we respect the design of general competencies, skills units and professional achievements with performance criteria proposed in the Spanish National Catalogue of Professional Qualifications, as well as the different existing guidelines in Spain and those proposed by various international organizations.

Taking as starting point the document from the Spanish National Institute of Vocational Qualifications, it is defined a structure of the professional qualifications that will serve to design programs, resources, methodologies and educational interventions. In this sense, we have made a major effort to assign to each qualification a general competence. This competence includes the roles and functions of the position and defines the specific skills or competency units. It is described also the professional environment in which you can develop the skills, relevant productive sectors and occupations or jobs relevant to access it.

Furthermore, in a complementary manner, we analyzed the professional achievements for each unit of competence along with their performance criteria.

The process started with the following situation:

- General competence is to distribute, reproduce and transmit the required information and documentation in the administrative and management task, internal and external, as well as to perform basic verification procedures on data and documents when senior technicians require it. These tasks are carried out in accordance with the existing instructions or procedures.

- Competence units are able to o provide support for basic administrative operations, to transmit and receive operational information to external agents to the organization and, finally, to perform auxiliary operations for reproduction and archiving data on conventional computational support.

- Professional field: This individual operates as an employee in any company or private/public entity, mainly in offices or departments oriented to administrative or general services.

- Productive Sectors: it appears in all the productive sectors, as well as public administration. It is necessary to remark the high degree of inter-sectoriality.

- Relevant occupations and positions are office assistant, general services assistant, file assistant, mail classifier and/or message, ordinance, information assistant, telephonist and ticket clerk.

However, looking for a more specific training support, it is necessary to complete this information with the detailed description of the most common tasks that arise in professional performance. Thus, describing the specific tasks, we have established the type of support that this group of disabled people requires to carry out an effective performance of the assigned tasks. 
Finally, we have established the most appropriate training strategies. Thus, we have described the most common tasks related to the professional profile and professional qualification presented in the previous table. The following example in Table 1 illustrates our proposal.

Table 1 Example of Competence Unit and Professional development

Competence Unit: To provide support for basic administrative operations.

Professional Development 1: To periodically register the Information updates of the organization, department, areas, personnel, according to the instructions previously received, with the aim of obtaining key Information to improve the existing services.

1. Make a list of phone and fax references of the various members of the company.

2. Update the directory of people.

3. To register the physical location of people and areas within the company.

4. To update the physical location of people and areas within the company.

5. Safe-keeping of keys.

6. Opening and closing the workplace and departments.

7. Bring documentation to other centers in the city (unions, Delegation, City Council, County Council, etc.).

8. Turn off and turn on the lights.

9. Opening and closing windows.

10. Open and lock any room.

11. To register the inputs and outputs of the employees.

12. To register a list for people who want to take the annual medical review.

\section{Technological Platform}

Based on the problem formalized in section 2 we obtained a technological platform,shown in Figure 1, which is based on Cloud Computing paradigm and it is specifically designed to create intelligent environments [8] oriented to facilitate the labor integration of people with auditory disabilities. From one side, the main objective of the Ambient Intelligence (AmI) is to achieve transparent and ubiquitous interaction of the user with the underlying technology [8]. From the other side, Cloud Computing is a model for enabling ubiquitous, convenient, on-demand network access to a shared pool of configurable computing resources [11].

In this paper we use AmI to design a software technology specialized on determining the professional qualification, and providing on-line tools focused on transmitting signed orders that are easily accessed via mobile devices. Meanwhile, the platform is deployed in +Cloud [11], which is a cloud computing platform. This platform offers services as Platform as a Service (PaaS) and Software as a Service (SaaS) level. The project developed in this study is deployed at SaaS level and it uses for data storage the services provides by the platform at PaaS, 
concretely the service OSS (Object Service Storage) which makes use a nonrelational database. And all educational resources are stored in the service FSS (File System Storage) provided by the platform.

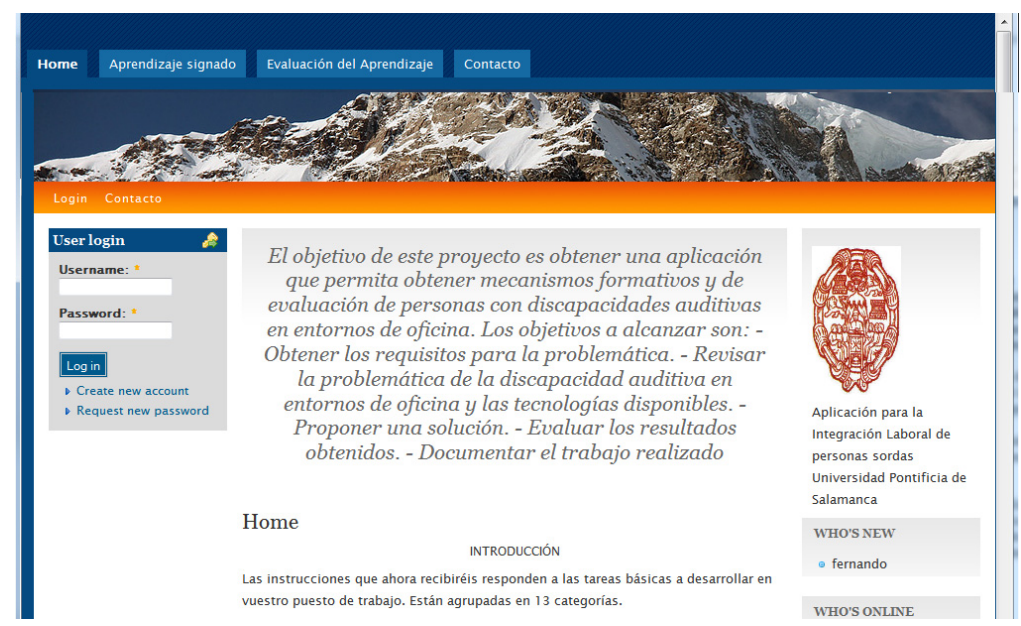

Fig. 1 Cloud-based platform

The functionality of the platform consists of a training web-based tool and a communication tool to send signed orders via mobile phone. Following it is described the main elements of the application:

- Order signing. Once the competences to evaluate were identified, and the related professional developments were defined, we proceeded to signing the actions and tasks that can be performed by the disabled person.To make the signing we counted on the cooperation of the Federation of the Deaf of Castile and Leon, who have participated in the signing process. The process followed consisted on recording a series of videos in which the sign interpreters transmit specific orders for each of the actions to be carried out by the disabled person. The recording was done in blocks, taking into account the professional developments taken into consideration. Once the recording process finished, we proceeded to edit the videos obtained by separating each action individually and including subtitles in Spanish.

- Web platform. In this task we obtained the design and development of a web platform that allows us to transmit work orders to the auditory disabled person using sign language format. The orders are transmitted via the Internet, television or mobile devices. The appearance of the platform is simple, trying to facilitate the accessibility and usability. The navigation through menus and contents is easy and intuitive. All the pages have been designed with the same structure, trying to facilitate a familiar environment and similar interaction patterns independently of the page or section in the platform. 
Once the user is in the learning section (see Figure 2), the learning process is started, displaying the videos for the different blocks of accomplishments that can occur in the office environment:
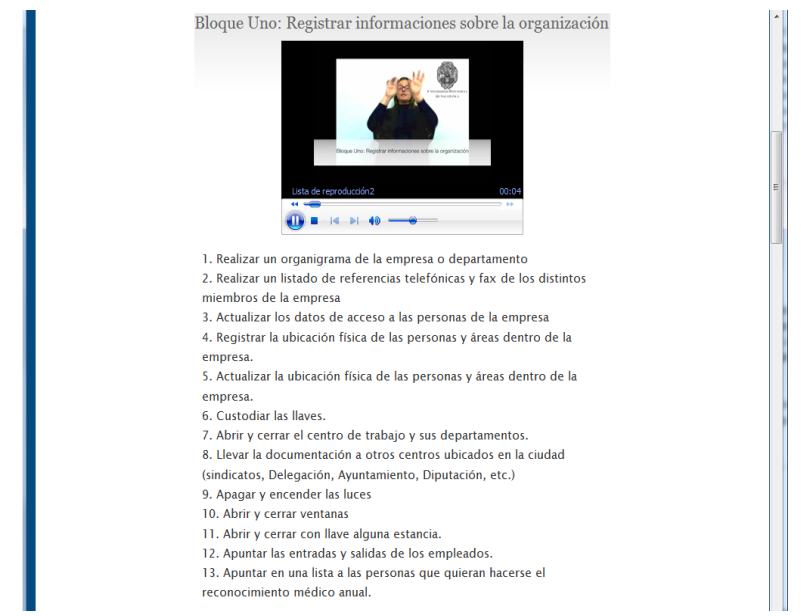

Fig. 2 Learning section

- Mobile application. In this work a mobile application had been developed for the platform that allows quick transmission of orders in the office workplace. The application includes voice recognition [9], so that a person at work may transmit voice instruction. These instructions will be recognized by the mobile device, which accesses a remote server and display the video corresponding to the order in sign language.

The related work and the existing technologies were revised in order to choose the best option for the mobile module. An analysis was made of all mobile platforms on the market to see which is more suited to our requirements. The module was developed for iOS, and can be installed on a device like iPad iPhone, as long as it has the same operating system version iOS 5 or above. This module uses an XML file containing the structure of the data to be displayed. This XML file is stored in the cloud, and is parsed by our application. When the application starts, it parses the file and inserts into a table all the blocks, so that the user can choose one of them. Once the user clicks on a block, a screen containing an explicative video will be shown. The videos are also stored in the cloud. The advantages of using cloud storage are that the content can be updated very easily and without jeopardizing the proper functioning of the application. Below, in Figure 3, some screenshots for the developed application are presented, showing its operation. 


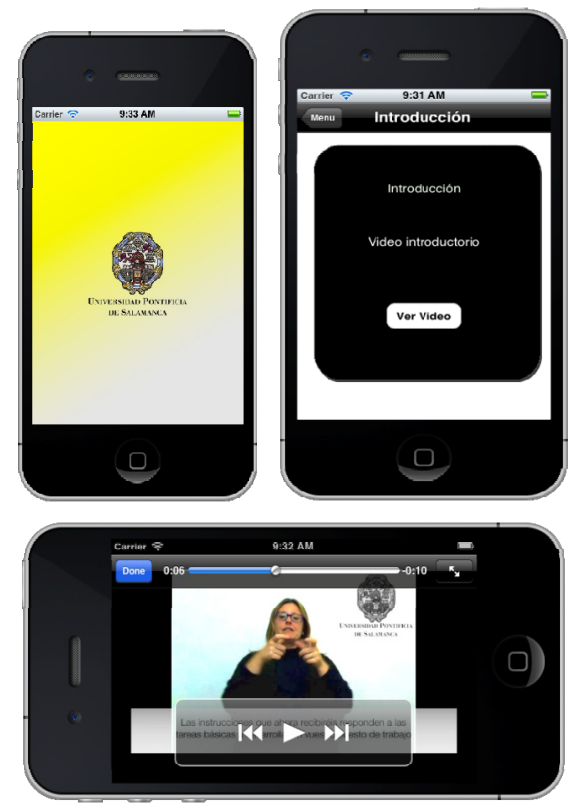

Fig. 3 Mobile application overview. Up-left: Main screen; Up-right: Block detail; Down: Signed video.

\section{Conclusions}

Our aim is to contribute to the goal of labor integration by means of a technological platform specifically designed to facilitate labor insertion in office environment of people with auditory impairment. The developed cloud-based platform has a web interface and an interface for mobile devices, and is based on prerecorded videos that contain instructions on actions to be performed by the disabled person in the office environment. The web interface was successfully tested in teaching through television, in collaboration with the company CSA and the results have been promising. Moreover, the mobile application was tested in an office environment. Users and FAPSCyL specialists have highlighted the utility and advantages of the application. A test was designed with 10 basic tasks performed by 3 disabled people before and after the platform presented in this paper was installed. The platform provided a new tool that contributed to increase the percentage of completed tasks up to $85 \%$, when the initial percentage (without the platform) was $42 \%$. The disabled users have remarked the ease of understanding of instructions they receive from their supervisors and ease of use of the system.

Acknowledgments. This research has been supported by the project SOCIEDADES HUMANO-AGENTE: INMERSION, ADAPTACION Y SIMULACION. TIN2012-36586C03-03funded by the Spanish Ministry of Science and Innovation. 


\section{References}

1. Calvo Prieto, J.C. (ed.): La sordera. Un enfoque socio-familiar. Amarú Ediciones, Salamanca (1999)

2. CNSE. Las personas sordas en España. Situación actual. Necesidades y demandas. Confederación Nacional de Sordos de España, Madrid (1996)

3. CNSE. Retos para el siglo XXI: Resoluciones del II Congreso de la Confederación de Sordos de España. Confederación Nacional de Sordos de España, Madrid (1998)

4. FESORCV. Minguet, A. (Coord.): Rasgos sociológicos y culturales de las personas sordas: una aproximación a la situación del colectivo de Personas Sordas en la Comunidad Valenciana. Federación de Personas Sordas de la Comunidad Valenciana (FESORD C.V.), Valencia (2001)

5. FIAPAS. Jáudenes (Coord.): Manual Básico de Formación Especializada sobre Discapacidad Auditiva. Confederación Española de Padres y Amigos de los Sordos, Madrid (2004)

6. Levy-Leboner, C.: Gestión de competencias. Gestión 2000, Barcelona (1997)

7. Ley 5/2002, de 19 de junio de las Cualificaciones y de la Formación Profesional. Madrid: BOE del 20 de junio de (2002)

8. Weiser, M.: The computer for the 21st century. Scientific American 265(3), 94-104 (1991)

9. Reynolds, D.A.: An overview of automatic speaker recognition technology. In: 2002 IEEE International Conference on Acoustics, Speech, and Signal Processing (ICASSP), vol. 4, pp. 4072-4075 (2002)

10. Mell, P., Grance, T.: The NIST definition of Cloud Computing. NIST Special Publication 800-145 (September 2011)

11. Heras, S., De la Prieta, F., Julian, V., Rodríguez, S., Botti, V., Bajo, J., Corchado, J.M.: Agreement technologies and their use in cloud computing environments. Progress in Artificial Intelligence 1(4), 277-290 (2012) 